\title{
An Outcome Measure of Functionality and Quality of Life in Patients With Cervical Myelopathy
}

\author{
Parisa Azimi ${ }^{1,}$; Omidvar Rezaei ${ }^{1}$; Ali Montazeri ${ }^{2}$ \\ ${ }^{1}$ Department of Neurosurgery, Shahid Beheshti University of Medical Sciences, Tehran, IR Iran \\ ${ }^{2}$ Mental Health Research Group, Health Metrics Research Centre, Iranian Institute for Health Sciences Research, The Academic Center for Education, Culture and Research, Tehran, \\ IR Iran \\ ${ }^{*}$ Corresponding Author: Parisa Azimi, Functional Neurosurgery Research Center, Shohada Tajrish Hospital, Shahid Beheshti University of Medical Sciences, Tehran, IR Iran. Tel: +98- \\ 2122749204, Fax:+98-2188265188, E-mail: parisa.azimi@gmail.com
}

Received: September 9, 2012; Revised: July 15, 2013; Accepted: April 9, 2014

\begin{abstract}
Background: Cervical spondylotic myelopathy (CSM) is a common cause of significant clinical morbidity. The Japanese Orthopedic Association Cervical Myelopathy Evaluation Questionnaire (JOACMEQ) is a measure of health-related quality of life in these patients.

Objectives: This study aimed to cross-culturally translate and validate the JOACMEQ in Iran.

Patients and Methods: This study was a prospective clinical validation one. Forward-backward procedure was applied to translate the questionnaire from English into Persian. The translation and cross-cultural adaptation were performed in accordance with the published guidelines. A sample of patients with CSM was asked to respond to the questionnaire at two times: providing preoperative and postoperative assessments (6 months follow-up). To test the reliability, the internal consistency was assessed by Cronbach $\alpha$ coefficient and the validity was assessed by convergent validity. Responsiveness to change was also assessed comparing patients' preoperative and postoperative scores.

Results: All 87 patients completed the questionnaire. The Cronbach $\alpha$ coefficient for the JOACMEQ at preoperative and postoperative assessments ranged from 0.71 to 0.82 indicating a good internal consistency for the questionnaire. In addition, the correlation of each item with its hypothesized subscale of the JOACMEQ showed satisfactory results suggesting that the items had a substantial association with their own subscales. Further analysis also indicated that the questionnaire was responsive to change $(\mathrm{P}<0.001)$.

Conclusions: In general, the findings suggest that the Persian version of the JOACMEQ is a reliable and valid measure of functionality and quality of life evaluation among Iranian patients suffered from CSM.
\end{abstract}

Keywords:Validation Studies as Topic; Spinal Cord Diseases; Iran

\section{Background}

Cervical spondylotic myelopathy (CSM) is a progressive degenerative disease of the cervical spine. It is usually a chronic and progressive disease. As people grow older, the prevalence of CSM increases (1). Thus, the assessment of functionality and pain in those who suffer from this disease is an important part of clinical practice. As such, the Japanese Orthopedic Association scoring system (JOA score) is a well-known instrument to assess functionality in this population. The JOA score was first established by a committee of the JOA chaired for assessment of cervical myelopathy (2-4). The JOA revised the JOA score for cervical spondylotic myelopathy and developed a new disease-specific, patient-oriented outcome measure. The Japanese Orthopedic Association Cervical Myelopathy Evaluation Questionnaire (JOACMEQ) has been validated as an outcome measure in these patients (5-9) and was used by Japanese investigators (10-12).

\section{Objectives}

The aim of this study was to translate the JOACMEQ into Persian, and then to use and validate the questionnaire in studies of functionality and quality of life in CSM affected patients in Iran.

\section{Patients and Methods}

\subsection{Questionnaire}

The Japanese Orthopedic Association Cervical Myelopathy Evaluation Questionnaire (JOACMEQ) is a revised version of the Japanese Orthopedic Association score (JOA). It was developed for the purpose of evaluating cervical myelopathy disorders (5-9). It is a self-administered, disease-specific tool and contains 24 items subdivided into five subscales: lower extremity function (5 items), quality of life (8 items), cervical spine function (4 items), 
bladder function ( 4 items), and upper extremity function ( 5 items). The score for each subscale ranges from 0 to 100 and higher scores indicate better conditions $(7,13)$. A user's guide and scoring manual for the JOACMEQ are available (13).

\subsection{Translation}

The 'forward-backward' procedure was applied to translate the JOACMEQ from English into Persian. Two general practitioners translated the questionnaire into Persian, and then the translated text was translated backward into English by a health professional and a professional translator. After a careful review, cultural adaptation, and few changes, a provisional Persian version of the questionnaire was provided.

The provisional version was tested on a number of patients in order to establish that patients could understand this version and that the questions measure what they are intended to measure. Most patients correctly understood the questionnaire. Their general comments about the difficulty of completing the questionnaire or understanding the texts were asked, and after a consensus by authors, the final version was developed.

\subsection{Patients and Data Collection}

A cross-sectional study was conducted and the final draft of the Persian version of the JOACMEQ was administered to a convenient sample of newly diagnosed CSM patients attending the neurosurgery clinic of a large teaching hospital in Tehran, Iran during May 2008 to November 2011. There were no restrictions on patient selection with regard to types of CSM, age or other characteristics. The exclusion criteria were prior cervical spine surgery and spinal anomalies.

It was estimated that a sample of 72 patients (at least 3 patients per item) would be enough to carry out psychometric tests as recommended (14). A trained neurosurgery resident collected the data during one complete calendar year. Patients were assessed at two points in time: preoperative and postoperative (6 months follow-up).

\subsection{Statistical Analysis}

\subsubsection{Reliability}

to test the reliability, the internal consistency of the questionnaire was measured using Cronbach $\alpha$ coefficient and $\alpha \geq 0.70$ was considered satisfactory (14).

\subsubsection{Validity}

Validity was assessed performing item-scale correlations. Correlations were calculated using Pearson's correlation coefficient $(r)$. It was expected that item scores would correlate higher with its own hypothesized scale than other scales. Correlation values of 0.40 or above were considered satisfactory ( $r \geq 0.81-1.0$ as excellent, $0.61-0.80$ very good, $0.41-0.60$ good, $0.21-0.40$ fair and 0.20 poor) (14).

\subsubsection{Responsiveness to Change}

Responsiveness as a psychometric property of the questionnaire was also assessed. As such, patients' preoperative and postoperative scores were compared using the paired t-test to examine whether JOACMEQ could capture the change after the intervention (surgery).

\subsection{Ethics}

The Ethics Committee of Shahid Beheshti University of Medical Sciences approved the study (dated 05.2008565523). All patients gave their informed consent after receiving both written and oral information about the project.

\section{Results}

A total of 96 patients were enrolled in the study. Of them, 87 patients completed the questionnaire and 9 patients were excluded due to prior cervical spine surgery or spinal anomalies. Table 1 shows the characteristics of the CSM patients and their scores on the JOACMEQ. The mean age of patients was $50.3(\mathrm{SD}= \pm 10.2$ ) years; most were married (73.6\%), and had completed primary or secondary education (69.0\%).

The internal consistency of the JOACMEQ as measured by the Cronbach $\alpha$ coefficient ranged from 0.72 to 0.80 at preoperative assessment and from 0.71 to 0.82 at postoperative evaluation indicating a satisfactory result. Table 2 presents the results.

Validity of the JOACMEQ was examined using item-scale correlations. Table 3 presents the item-scale correlation matrix between each item and the five subscales of the JOACMEQ. All correlations between items and their hypothesized scales showed satisfactory results suggesting that the items had a substantial association with their own subscale. Pearson correlation coefficient exceeded the recommended level $(r \geq 0.40)$ ranging from 0.49 (Q2-4) to 0.80 (Q1-8). Responsiveness to change was assessed by paired t-test. In all instances, the JOACMEQ could detect changes after the intervention (surgery) indicating improvements in all subscales as expected. Table 4 shows the results.

\section{Discussion}

The results of the present study showed that the Persian version of the JOACMEQ is a reliable measure to evaluate functionality and quality of life in Persian-speaking patients with cervical myelopathy. As noted by its authors the JOACMEQ measures five factors and the score for each factor should be interpreted independently. The total score for the JOACMEQ was considered meaningless $(7,13)$. 


\begin{tabular}{lc}
\hline Table 1. The Characteristics of the Study Sample $(\mathrm{n}=87)^{\mathrm{a}}$ & \\
\hline- & Values \\
\hline Age Groups, $\mathbf{y}$ & $50.3 \pm 10.2$ \\
\hline Mean \pm SD & $24-79$ \\
\hline Range & $39(44.8)$ \\
\hline Gender & $48(55.2)$ \\
\hline Male & \\
\hline Female & $14(16.1)$ \\
\hline Educational status & $38(43.7)$ \\
\hline Illiterate & $22(25.3)$ \\
\hline Primary School & $13(14.9)$ \\
\hline Secondary School & \\
\hline College/university & $15(17.2)$ \\
\hline Marital status & $64(73.6)$ \\
\hline Single & $8(9.2)$ \\
\hline Married & \\
\hline Divorced/Widowed & $50(57.5)$ \\
\hline Type of disease & $37(42.5)$ \\
\hline Cervical herniated disk & \\
\hline Cervical spinal stenosis & \\
\hline Dateprenter & \\
\hline
\end{tabular}

\footnotetext{
${ }^{\mathrm{a}}$ Data are presented as No. (\%).
}

Table 2. Descriptive Statistics

\begin{tabular}{|c|c|c|c|c|c|}
\hline- & Number of Items & $\begin{array}{c}\text { Cronbach } \alpha \text { Coef- } \\
\text { ficient }{ }^{\mathrm{a}} \text { (Preopera- } \\
\text { tive) }\end{array}$ & $\begin{array}{c}\text { Cronbach } \alpha \text { Coef- } \\
\text { ficient }{ }^{\mathrm{a}} \text { (Postop- } \\
\text { erative) }\end{array}$ & Floor Effect (\%) & Ceiling Effect (\%) \\
\hline Lower extremity function & 5 & 0.75 & 0.82 & 0 & 0 \\
\hline Quality of life & 8 & 0.80 & 0.79 & 1.140 & 0 \\
\hline Cervical spine function & 4 & 0.78 & 0.77 & 0 & 0 \\
\hline Bladder function & 4 & 0.74 & 0.76 & 0 & 0 \\
\hline Upper extremity function & 5 & 0.72 & 0.71 & 0 & 0 \\
\hline
\end{tabular}

${ }^{\mathrm{a}}$ A value of 0.70 or above indicates adequate reliability.

Table 3. Item-Scale Correlation Matrix for the Five JOACMEQ Subscales ${ }^{\text {a }}$

\begin{tabular}{|c|c|c|c|c|c|}
\hline Items (Item Number) & $\begin{array}{l}\text { Lower Extrem- } \\
\text { ity Function }\end{array}$ & Quality of Life & $\begin{array}{l}\text { Cervical Spine } \\
\text { Function }\end{array}$ & Bladder Function & $\begin{array}{l}\text { Upper Extremity } \\
\text { Function }\end{array}$ \\
\hline $\begin{array}{l}\text { Can you walk on a flat surface? } \\
\text { (Q1-4) }\end{array}$ & 0.64 & 0.18 & 0.18 & 0.16 & 0.66 \\
\hline $\begin{array}{l}\text { Can you stand on either leg } \\
\text { without holding onto some- } \\
\text { thing?(Or the need to support } \\
\text { yourself).(Q1-5) }\end{array}$ & 0.63 & 0.24 & 0.25 & 0.20 & 0.14 \\
\hline Do you have difficulty in climb- & 0.51 & 0.26 & 0.28 & 0.22 & 0.24 \\
\hline
\end{tabular}

ing up the stairs? (Q2-2) 
Azimi P et al.

\begin{tabular}{|c|c|c|c|c|c|}
\hline $\begin{array}{l}\text { Do you have difficulty with } \\
\text { one of the following: bending } \\
\text { forward, kneeling or stooping? } \\
\text { If you have difficulty with one of } \\
\text { them, how difficult is it? (Q2-3) }\end{array}$ & 0.52 & 0.32 & 0.19 & 0.33 & 0.16 \\
\hline $\begin{array}{l}\text { Do you have difficulty walking } \\
\text { more than } 15 \text { minutes? (Q2-4) }\end{array}$ & 0.49 & 0.55 & 0.27 & 0.10 & 0.26 \\
\hline $\begin{array}{l}\text { How is your present health } \\
\text { condition? (Q2-1) }\end{array}$ & 0.24 & 0.59 & 0.17 & 0.24 & 0.32 \\
\hline $\begin{array}{l}\text { Have you been unable to do } \\
\text { your work or ordinary activities } \\
\text { as well as you would like? (Q2-5) }\end{array}$ & 0.22 & 0.68 & 0.19 & 0.31 & 0.24 \\
\hline $\begin{array}{l}\text { Has your work routine been } \\
\text { hindered because of the pain? } \\
\text { (Q2-6) }\end{array}$ & 0.18 & 0.70 & 0.24 & 0.14 & 0.25 \\
\hline $\begin{array}{l}\text { Have you felt discouraged and } \\
\text { depressed? (Q2-7) }\end{array}$ & 0.27 & 0.68 & 0.23 & 0.19 & 0.12 \\
\hline Do you feel exhausted? (Q2-8) & 0.24 & 0.59 & 0.27 & 0.27 & 0.24 \\
\hline Have you felt happy? (Q2-9) & 0.31 & 0.51 & 0.23 & 0.26 & 0.14 \\
\hline $\begin{array}{l}\text { Do you think you are in decent } \\
\text { health? (Q2-10) }\end{array}$ & 0.24 & 0.62 & 0.18 & 0.31 & 0.22 \\
\hline $\begin{array}{l}\text { Do you feel your health will get } \\
\text { worse? (Q2-11) }\end{array}$ & 0.14 & 0.69 & 0.26 & 0.33 & 0.27 \\
\hline $\begin{array}{l}\text { While in the sitting position, } \\
\text { can you look up at the ceiling } \\
\text { by tilting your head upward? } \\
\text { (Q1-10) }\end{array}$ & 0.18 & 0.26 & 0.55 & 0.14 & 0.26 \\
\hline $\begin{array}{l}\text { Can you drink a glass of water } \\
\text { without stopping despite the } \\
\text { neck symptoms? (Q1-11) }\end{array}$ & 0.30 & 0.19 & 0.74 & 0.16 & 0.18 \\
\hline $\begin{array}{l}\text { Can you look at your feet when } \\
\text { you go down the stairs? (Q1-12) }\end{array}$ & 0.27 & 0.35 & 0.78 & 0.25 & 0.67 \\
\hline While in the sitting position, & 0.19 & 0.31 & 0.73 & 0.28 & 0.21 \\
\hline
\end{tabular}

can you turn your head toward

the person who is seated to the

side but behind you and speak

to that person while looking at

his/her face? (Q1-13)

Do you have urinary inconti-

nence? (Q1-6)

How often do you go to the

bathroom at night? (Q1-7)

Do you have a feeling of residua

urine in your bladder after void-

ing?(Q1-8)

Can you initiate (start) your

urine stream immediately

when you want to void? (Q1-9)

\begin{tabular}{|c|c|c|c|c|c|}
\hline $\begin{array}{l}\text { Can you fasten the front but- } \\
\text { tons of your blouse or shirt with } \\
\text { both hands? (Q1-1) }\end{array}$ & 0.25 & 0.14 & 0.09 & 0.24 & 0.78 \\
\hline $\begin{array}{l}\text { Can you eat a meal with your } \\
\text { dominant hand using a spoon } \\
\text { or a fork? (Q1-2) }\end{array}$ & 0.11 & 0.26 & 0.15 & 0.28 & 0.69 \\
\hline $\begin{array}{l}\text { Can you raise your arm? (An- } \\
\text { swer for the weaker side.) (Q1-3) }\end{array}$ & 0.18 & 0.19 & 0.19 & 0.32 & 0.58 \\
\hline
\end{tabular}

swer for the weaker side.) (01-3)

$\begin{array}{lllll}0.32 & 0.14 & 0.16 & 0.67 & 0.20 \\ 0.14 & 0.26 & 0.24 & 0.76 & 0.21 \\ 0.22 & 0.10 & 0.22 & 0.80 & 0.25 \\ 0.24 & 0.27 & 0.18 & 0.69 & 0.20\end{array}$

a Pearson correlation $(r)$ equal to or greater than 0.40 was considered satisfactory. (Correlation $\geq 0.81-1.0$ as excellent, 0.61-0.80 very good, 0.41-0.60 good, 0.21-0.40 fair, and 0.0-0.20 poor) (14). 
Azimi P et al.

Table 4. Responsiveness to Change as Measured by the JOACMEQ ${ }^{a}$

\begin{tabular}{|c|c|c|c|}
\hline & Preoperative & Postoperative & P Value $^{\mathrm{b}}$ \\
\hline Lower extremity function & $41.3 \pm 24.3$ & $69.7 \pm 11.2$ & $<0.001$ \\
\hline Quality of life & $32.4 \pm 25.6$ & $56.1 \pm 7.6$ & $<0.001$ \\
\hline Cervical spine function & $51.1 \pm 29.3$ & $76.9 \pm 9.3$ & $<0001$ \\
\hline Bladder function & $61.3 \pm 19.3$ & $79.3 \pm 7.3$ & $<0.001$ \\
\hline Upper extremity function & $48.4 \pm 15.4$ & $59.1 \pm 12.4$ & $<0.001$ \\
\hline
\end{tabular}

a Data are presented as mean \pm SD.

$\mathrm{b}$ Derived from paired t-test samples.

The Cronbach $\alpha$ for the Persian version of the JOACMEQ exceeded the recommended threshold suggesting that the Persian version of the questionnaire has satisfactory internal consistency. However, our approach for testing reliability of the JOACMEQ was different from the pioneering designers of the questionnaire. According to their report, each patient was interviewed twice at an interval of 4 weeks and then, the reliability of the questionnaire was evaluated by determining the extension of the weighted kappa coefficient. They reported that the weighted kappa was more than 0.50 for all but one item, which was 0.49 (7).

To the best of authors' knowledge, the Persian version of the JOACMEQ is the only condition-specific outcome measure for patients with CSM that was undergone psychometric evaluation in Iran. In addition, as far as we know, this research is the first attempt in the literature for translating and validating the JOACMEQ.

According to our results, this instrument seems to be a reliable and valid outcome measure for functionality and quality of life in patients with cervical myelopathy in Iran, and perhaps it could be validated in other languages to compare the results of possible upcoming studies. The JOACMEQ offers an effective method of evaluation for quality of life (12) and as suggested it is likely that the JOACMEQ succeeds and becomes a global standard to evaluate outcomes in patients with cervical myelopathy (6).

We carried out a number of limited tests to perform this validation study. In future, it might be necessary to perform other tests to establish stronger psychometric indexes for the JOACMEQ. Perhaps one might argue why the authors did not perform explanatory factor analysis (EFA) and confirmatory factor analysis (CFA) to ensure that the questionnaire fits to the data.

In response, we should indicate that the questionnaire and its scoring procedure does not allow performing such analyses. For instance, there are items that should be included in different subscales. In addition, when calculating scores for subscales, all items should be multiplied by a given number. The scoring manual could be found in Appendix 1. Finally, we state that even the designers of the questionnaire did not perform any of the above analyses. The findings from this preliminary validation study indicate that the Persian version of the JOACMEQ is a reli- able and valid instrument for measuring functionality and quality of life in patients with cervical myelopathy.

\section{Appendix:}

Scoring manual for the JOACMEQ:

Cervical spine function;

$(\mathrm{Q} 1-10 \times 20+\mathrm{Q} 1-11 \times 10+\mathrm{Q} 1-13 \times 15+\mathrm{Q} 1-12 \times 5-50)$

Upper extremity function;

$(\mathrm{Q} 1-12 \times 5+\mathrm{Q} 1-1 \times 10+\mathrm{Q} 1-2 \times 15+\mathrm{Q} 1-3 \times 5+\mathrm{Q} 1-4 \times 5-40)$

$\times 100 \div 95$

Lower extremity function;

$(\mathrm{Q} 1-4 \times 10+\mathrm{Q} 1-5 \times 10+\mathrm{Q} 2-2 \times 15+\mathrm{Q} 2-3 \times 5+\mathrm{Q} 2-4 \times 5-45)$

$\times 100 \div 110$

Bladder function;

$(\mathrm{Q} 1-6 \times 10+\mathrm{Q} 1-7 \times 5+\mathrm{Q} 1-8 \times 10+\mathrm{Q} 1-9 \times 5-30) \times 100 \div 80$

Quality of life;

$(\mathrm{Q} 2-1 \times 3+\mathrm{Q} 2-5 \times 2+\mathrm{Q} 2-6 \times 2+\mathrm{Q} 2-7 \times 5+\mathrm{Q} 2-8 \times 4+\mathrm{Q} 2-9 \times$ $3+\mathrm{Q} 2-10 \times 2+\mathrm{Q} 2-11 \times 3-24) \times 100 \div 96$

\section{Acknowledgements}

The authors thank the staff of the Neurosurgery Unit at Imam Hossein Hospital, Tehran, Iran.

\section{Authors' Contribution}

All authors contributed equally.

\section{Financial Disclosure}

There was no conflict of interest.

\section{Funding/Support}

There was no support.

\section{References}

1. Traynelis VC, Arnold PM, Fourney DR, Bransford RI, Fischer DJ, Skelly AC. Alternative procedures for the treatment of cervical spondylotic myelopathy: arthroplasty, oblique corpectomy, skip laminectomy: evaluation of comparative effectiveness and safety. Spine (Phila Pa 1976). 2013;38(22 Suppl 1):S210-31.

2. Japanese Orthopaedic Association. [Japanese Orthopaedic Association scoring system for cervical spondylotic myelopathy]. JJpn Orthop Assoc. 1976;50:18-9.

3. Japanese Orthopaedic Association. [Scoring system (17-2) for cer- 
vical myelopathyl. J Jpn Orthop Assoc. 1994;68:490-503.

4. Yonenobu K, Abumi K, Nagata K, Taketomi E, Ueyama K. Interobserver and intraobserver reliability of the japanese orthopaedic association scoring system for evaluation of cervical compression myelopathy. Spine (Phila Pa 1976). 2001;26(17):1890-4.

5. Fukui M, Chiba K, Kawakami M, Kikuchi S, Konno S, Miyamoto $\mathrm{M}$, et al. An outcome measure for patients with cervical myelopathy: Japanese Orthopaedic Association Cervical Myelopathy Evaluation Questionnaire (JOACMEQ): Part 1. J Orthop Sci. 2007;12(3):227-40

6. Fukui M, Chiba K, Kawakami M, Kikuchi S, Konno S, Miyamoto M, et al. Japanese Orthopaedic Association Cervical Myelopathy Evaluation Questionnaire (JOACMEQ): Part 2. Endorsement of the alternative item. JOrthop Sci. 2007;12(3):241-8.

7. Fukui M, Chiba K, Kawakami M, Kikuchi S, Konno S, Miyamoto M, et al. Japanese Orthopaedic Association Cervical Myelopathy Evaluation Questionnaire: part 3. Determination of reliability. $J$ Orthop Sci. 2007;12(4):321-6.

8. Clinical Outcomes Committee of the Japanese Orthopaedic Association SOEOBP, Cervical M, Subcommittee on Low Back P, Cervical Myelopathy Evaluation of the Clinical Outcome Committe of the Japanese Orthopaedic A, Fukui M, Chiba K, et al. JOA back pain evaluation questionnaire: initial report. J Orthop Sci. 2007;12(5):443-50.

9. Fukui M, Chiba K, Kawakami M, Kikuchi S, Konno S, Miyamoto M, et al. Japanese Orthopaedic Association Cervical Myelopathy Evaluation Questionnaire (JOACMEQ): part 4. Establishment of equations for severity scores. Subcommittee on low back pain and cervical myelopathy, evaluation of the clinical outcome committee of the Japanese Orthopaedic Association. J Orthop Sci. 2008;13(1):25-31.

10. Nakashima H, Yukawa Y, Ito K, Machino M, Kanbara S, Morita D, et al. Validity of the 10-s step test: prospective study comparing it with the 10-s grip and release test and the 30-m walking test. Eur Spine J. 2011;20(8):1318-22.

11. Nakashima H, Yukawa Y, Ito K, Machino M, Kanbara S, Morita D, et al. Prediction of lower limb functional recovery after laminoplasty for cervical myelopathy: focusing on the 10-s step test. Eur Spine J. 2012;21(7):1389-95.

12. Nikaido T, Kikuchi S, Yabuki S, Otani K, Konno S. Surgical treatment assessment using the Japanese orthopedic association cervical myelopathy evaluation questionnaire in patients with cervical myelopathy: a new outcome measure for cervical myelopathy. Spine (Phila Pa 1976). 2009;34(23):2568-72.

13. Fukui M, Chiba K, Kawakami M, Kikuchi S, Konno S, Miyamoto M, et al. JOA Back Pain Evaluation Questionnaire (JOABPEQ)/JOA Cervical Myelopathy Evaluation Questionnaire (JOACMEQ). The report on the development of revised versions. April 16, 2007 The Subcommittee of the Clinical Outcome Committee of the Japanese Orthopaedic Association on Low Back Pain and Cervical Myelopathy Evaluation. J Orthop Sci. 2009;14(3):348-65.

14. Nunnally JC, Bernstien IH. Psychometric Theory. 3rd edNew York: McGraw-Hill; 1994 